\title{
Proceedings of the AMCP Partnership Forum: Breaking the Link Between Pain Management and Opioid Use Disorder
}

\begin{abstract}
SUMMARY
Prescription drug misuse and abuse, especially with opioid analgesics, is the fastest growing drug problem in the United States. Addressing this public health crisis demands the coordinated efforts and actions of all stakeholders to establish a process of improving patient care and decreasing misuse and abuse. On September 9, 2014, the Academy of Managed Care Pharmacy (AMCP) convened a meeting of multiple stakeholders to recommend activities and programs that AMCP can promote to improve pain management, prevent opioid use disorder (OUD), and improve medicationassisted treatment outcomes.

The speakers and panelists recommended that efforts to improve pain management outcomes and reduce the potential for OUD should rely on demonstrated evidence and best practices. It was recommended that AMCP promote a more holistic and evidence-based approach to pain management and OUD treatment that actively engages the patient in the decision-making process and includes care coordination with medical, pharmacy, behavioral, and mental health aspects of organizations, all of which is seamlessly supported by a technology infrastructure. To accomplish this, it was recommended that AMCP work to collaborate with organizations representing these stakeholders. Additionally, it was recommended that AMCP conduct continuing pharmacy education programs, develop a best practices toolkit on pain management, and actively promote quality standards for OUD prevention and treatment.
\end{abstract}

J Manag Care Spec Pharm. 2015;21(12):1116-22

Copyright $\odot 2015$, Academy of Managed Care Pharmacy. All rights reserved.

$\mathrm{I}$ $\mathrm{n}$ the past decade, prescription drug misuse and abuse, especially of opioid analgesics, has been the fastest growing drug problem in the United States and has high societal and economic costs. ${ }^{1-4}$ In some individuals, misuse and abuse of opioids can lead to opioid overdose deaths, as well as generate costs to the health care, workplace, and criminal justice systems. ${ }^{2,5}$ Patients' access to safe and effective pharmacological pain management should therefore be coupled with prudent measures to minimize the chance of unintended consequences such as opioid use disorder (OUD) and opioid-related death. ${ }^{6}$ Addressing this public health crisis demands coordinated efforts and actions on the part of all stakeholders in order to improve patient care and decrease misuse and abuse. On September 9, 2014, the Academy of Managed Care Pharmacy (AMCP) held a Partnership Forum entitled "Breaking the Link Between Pain Management and Opioid Use Disorder." The forum brought together multiple stakeholders from managed care organizations (MCOs), pharmacy benefit managers, community and specialty pharmacies, medication therapy management (MTM) vendors, federal government agencies, OUD specialists, medical societies, patient advocacy groups, and pharmaceutical manufacturers and researchers.

\section{Purpose and Discussion Topics}

The goal of the forum was to recommend activities and programs that AMCP can promote to improve pain management, prevent OUD, and improve OUD treatment outcomes. In view of that goal, the following topics were discussed:

1. From managed care and patient perspectives, how do we not repeat the past?

2. Are our organizations maximizing internal and external sources (including MTM) and working collaboratively to prevent OUD?

3. Are our organizations managing internal and external resources (e.g., behavioral health, physical therapy, and treatment centers) effectively to treat OUD?

4. What would external partners and patients ask you to change about your approach?

\section{Opioid Use Disorder as a Public Health Crisis}

The scope of OUD was reviewed at the forum by Speaker Michael Botticelli, director of the White House Office of National Drug Control Policy. ${ }^{7}$ Of the 41,340 drug overdose deaths in 2011 in the United States, 41\% involved prescription drugs, with the vast majority (71\%) being opioid analgesics. ${ }^{8}$ Another 22\% involved cocaine (11\%) and heroin (11\%). A 2007 study estimated costs for prescription drug abuse of $\$ 55.7$ billion, including $\$ 25$ billion in direct health care costs and $\$ 5.1$ billion in criminal justice costs. ${ }^{2}$ Other studies found that the average individual abusing opioids has annual direct health care costs that are 8.7 times higher than nonabusers. ${ }^{5}$

While only a small fraction of nonmedical pain reliever (NMPR) users (3.6\%) initiated heroin use, prescription opioid use is a risk factor for heroin use. Approximately $80 \%$ of heroin users used NMPRs before heroin initiation. ${ }^{9}$ Recent research shows that individuals who formerly abused prescription opioids are motived to move to heroin because of price, availability, ease of use, and enhanced effects. ${ }^{10}$

\section{U.S. National Drug Control Strategy 2014}

In response to the current public health crisis, the Obama Administration's U.S. National Drug Control Strategy emphasizes preventing drug use through education. ${ }^{11}$

Part of President Barack Obama's science-based plan is to reform drug policy by (a) expanding access to treatment for Americans struggling with addiction, (b) reforming our criminal justice system, and (c) supporting Americans in recovery. 
The U.S. National Drug Control Strategy presents 4 objectives for preventing prescription drug abuse: (1) education, (2) prescription drug monitoring programs (PDMP), (3) proper disposal of medication, and (4) enforcement.

To accomplish these objectives, more research is needed on effective strategies for reducing overdose and the prevalence of substance use disorders.

\section{The Perfect Storm}

Speaker Beth Tanzman, assistant director of Vermont Blueprint for Health, explored the factors that have contributed to the current epidemic of unintentional overdose deaths to which opioid analgesics contribute. ${ }^{12}$ The health care community usually attributes the prevalence of OUD to an overreliance on opioids for pain relief. The following additional contributing factors were identified:

- Increasing rates of opioid prescribing.

- Inadequate network capacity for OUD treatment.

- High health care expenditures for OUD treatment.

- Poor patient outcomes with OUD treatment.

- Program and funding silos.

- Lack of an evidence-based medicine approach to pain management and OUD.

\section{AHRO Systematic Review}

In considering an evidence-based medicine approach, speakers and panelists discussed the Agency for Healthcare Research and Quality (AHRQ) 2014 systematic review "The Effectiveness and Risks of Long-Term Opioid Treatment of Chronic Pain."13 This review emphasized that lack of strong evidence has hindered our response to "the dramatic increase in overdose deaths associated with opioids." In particular, this report noted that evidence is insufficient in these following areas:

1. Effectiveness of risk prediction tools at predicting risk for, reducing the rates of, or improving outcomes related to opioid overdose, addiction, abuse, or misuse.

2. Effectiveness of risk mitigation strategies, including abuse deterrent formulations, urine drug screenings, prescription drug monitoring program data, monitoring instruments, and opioid management plans.

3. Comparative effectiveness of treatment options for opioid addiction lack the rigor necessary to provide definitive pathways.

The AHRQ review also noted that there is limited evidence to support the abundant use of prescription opioids. It found the strength of evidence low for the following:

1. Effectiveness of long-term opioid therapy versus placebo for more than 1 year.
2. Comparative effectiveness of opioids versus nonopioid therapies on pain, function, and quality of life.

3. Comparative effectiveness of short- versus long-term opioid use on outcomes related to pain, function, quality of life, risk of overdose, addiction, and abuse.

\section{Pain Management Should Emphasize OUD Prevention}

Through discussion, the speakers and panelists defined the starting point for preventing OUD as the understanding that all opioid users are at risk, not just chronic pain patients. ${ }^{14,15}$ Data from the Office of National Drug Control Policy demonstrate that friends and relatives remain a major source of opioids for nonmedical use but physician prescribing accounts for $17 \%$ $26 \%$ of the sourcing (Figure 1). ${ }^{16}$

\section{Role of P\&T Committees}

Given this starting point, Speaker Jessica Daw, director of Clinical Pharmacy at the University of Pittsburgh Medical Center (UPMC) Health Plan recommended that pharmacy and therapeutics (P\&T) committees rely on evidence-based medicine to drive their decisions about pain treatment. ${ }^{17}$ In the past, Daw posited, we relied on pain guidelines that were supported by a low level of evidence for long-term opioid use. Now, she noted that while abuse-deterrent formulations are coming to the market, there are limited well-designed studies proving that these formulations have reduced the likelihood of OUD. She and other panelists recommended that if these new products are added to coverage or to formularies, P\&T committees should require reviews of real-world data after implementation.

The UPMC P\&T Committee has implemented a variety of prevention strategies, including the following:

- Limits on days supply, quantity, and prescriptions.

- Prior authorization, including compounded products and long-acting products.

- Concurrent drug utilization review (DUR) and fraud waste and abuse programs that target high-user patients, pharmacies, and physicians. These programs included targets identified by the Centers for Medicare \& Medicaid Services (CMS) Overutilization Monitoring System (OMS).

- Lock-in programs, including beneficiary-level point-ofservice edits.

- Management of nonparticipating providers.

UPMC also launched a physician toolkit, developed with the assistance of network pain specialists that includes the following:

- Patient assessment guidelines.

- Summary of pain etiology and treatment options.

- Acute pain strategies and resources for management and follow-up.

- Chronic pain strategies and resources for management and follow-up. 


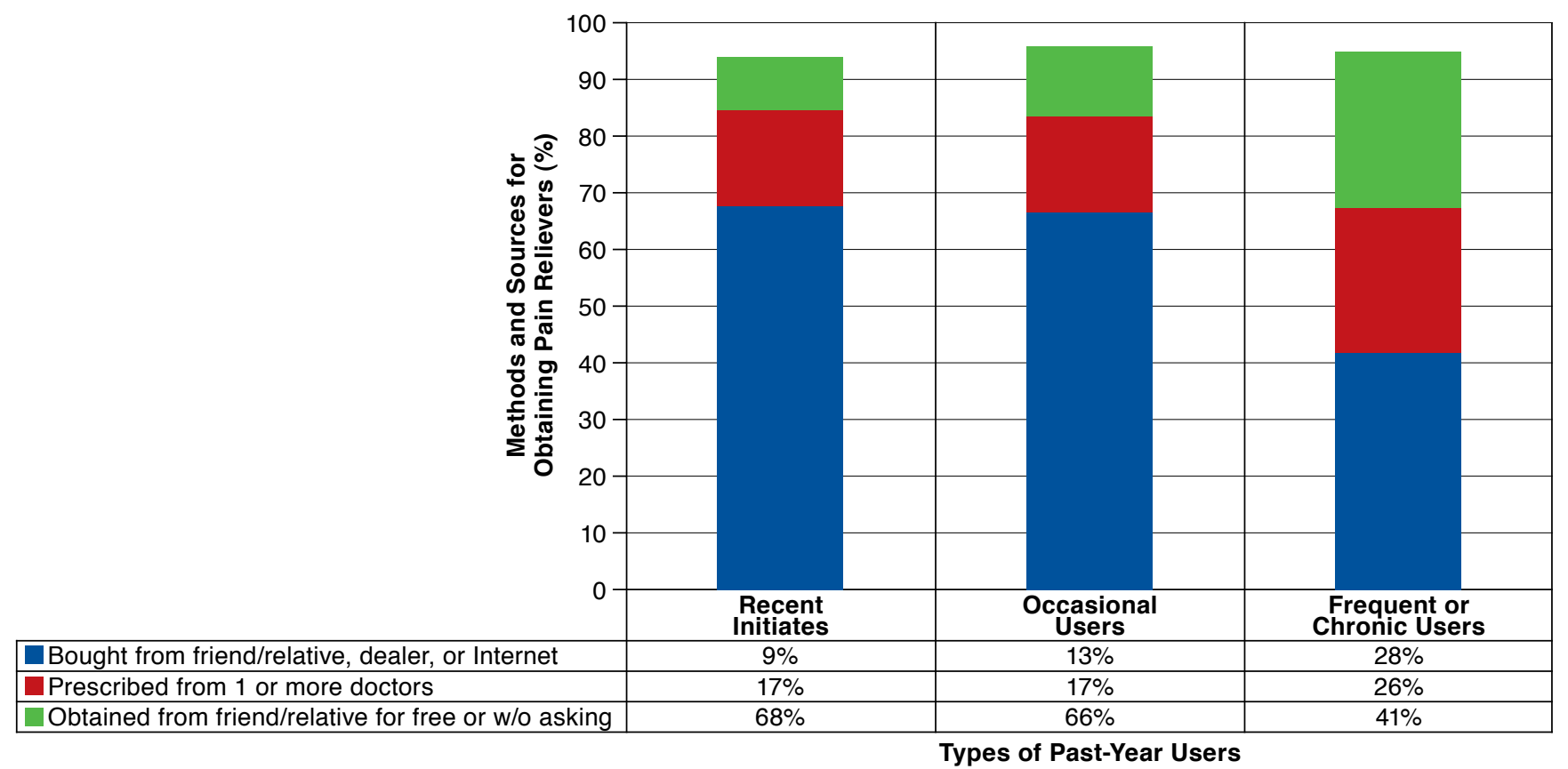

Source: Office of National Drug Control Policy, Office of Public Affairs. Fact sheet: opioid abuse in the United States. ${ }^{16}$ Data from SAMHSA, Center for Behavioral Health Statistics and Quality, National Survey on Drug Use and Health, 2009-2010.

- Tools for proper documentation and pain management.

- Multidisciplinary team support and referral options.

- Equi-analgesic dosing chart.

\section{Beyond P\&T Committees}

Speaker Thomas Kowalski, director of Clinical Pharmacy for Blue Cross Blue Shield of Massachusetts (BCBSMA), detailed a systemwide approach that BCBSMA took with its OUD prevention efforts. BCBSMA convened advisory groups that consisted of network pain management providers, addiction experts, pharmacists, and primary care providers to define best practices in opioid management. ${ }^{18}$ Three key opioid interventions were identified: quantity level limits and prior authorization (PA) requirements for opioids, medication-assisted treatment (MAT) drugs, and laboratory testing. The specific restrictions included the following:

- A 15-day supply limit on initial prescriptions of shortacting opioids. Patients with cancer and terminal illness are excluded. PA is required for subsequent opioid prescriptions that exceed a 30-day supply in a rolling 60-day period. Authorization is based on existence of evidence-based opioid- prescribing elements (i.e., informed consent on risks, risk assessment for addiction, provider-patient opioid agreement, defined limited prescribing group, and identification of single pharmacy or chain).
- PAs grant access to a 15-day supply of all short-acting opioids on BCBSMA formularies. Additional 15-day supplies within 60 days are allowed to a maximum of a 30-day supply in a rolling 60-day period. Beyond this, an authorization is required, but if a PA is not available at the point of sale, the member receives a 3-day supply of the short-acting opioid. This allows sufficient time for an authorization to be obtained.

- For long-acting opioids, providers must document that the elements of evidence-based opioid prescribing were followed and give a trial of short-acting opioids (or a reason why this is inappropriate).

- MAT drugs (e.g., buprenorphine) require PA with physician verification of the evidence-based elements of opioid prescribing and assessment of a member's access to behavioral health support.

To support these strategies, BCBSMA uses the CMS OMS quarterly reports and monthly provider reporting. The OMS provides quarterly reports to Part D plan sponsors on beneficiaries who received opioids in excess of 120 milligrams morphine equivalent dose for 90 consecutive days from 4 or more prescribers and 4 or more pharmacies in a 1-year period, and acetaminophen use that exceeds a daily dose of 4 grams for 30 days in a 6 -month period. ${ }^{19}$ Provider reports detail any 
member receiving more than 2 prescriptions from more than 2 prescribers and more than 2 pharmacies. These combined strategies dropped members receiving opioids by $7.2 \%$ and opioid claims by $8.3 \%$ in a 12 -month period.

Speakers and panelists noted that, while slow in coming, U.S. Food and Drug Administration (FDA) prevention strategies are having some impact. The FDA enacted risk evaluation and mitigation strategies (REMS) for extended-release/longacting opioids; whether there are better ways to look at addiction and overdose rates and other outcome measures is being asked. ${ }^{20,21}$ Generally, speakers and panelists agreed that the FDA-recommended rescheduling of all hydrocodone products to Schedule II could have a positive impact on OUD decline.

Speakers and participants discussed other recent federal and state calls to action that have been experiencing some success. Prescription drug monitoring programs (PDMP) are being operationalized in every state, with interoperability among states. Tennessee's PDMP law requiring prescribers to access the PDMP before prescribing opioids to a new patient demonstrates the potential for PDMPs: the number of high opioid users (defined as a person who used 5 prescribers and 5 pharmacies in a 90-day period) decreased by $47 \% .{ }^{22}$ Additionally, promotion of lock-in programs, with the understanding that optimal program design and coordination with other OUD policies should continue to be explored, was advocated. ${ }^{23}$ Similarly, the CMS OMS, instituted partly in response to GAO-11-699which found that 170,000 beneficiaries received medicines from 5 or more prescribers ${ }^{24}$-is showing a reduction in the overuse of opioids and acetaminophen in Medicare Part D. ${ }^{19}$

\section{Identifying and Treating Opioid Use Disorder}

The scope of illicit drug use in the United States is alarming. An estimated 8.7 million persons aged 12 years or older (3.3\%) were current users of illicit drugs other than marijuana in $2013 .{ }^{25}$ The majority $(2.5 \%, 6.5$ million) of these users were nonmedical users of psychotherapeutic drugs, including 4.5 million users of pain relievers and tranquilizers $(1.7 \%)$ and stimulants $(0.5 \%)$. According to Speaker Michael Duggan, founder of Wicked Sober, a support group for patients with OUD, patient denial is another equally concerning stumbling block to our ability to stem this epidemic. ${ }^{15}$ This concern was confirmed by the 2013 National Survey on Drug Use and Health: among illicit drug users, 95\% did not feel they needed treatment. ${ }^{25}$ Only $1.6 \%$ of illicit users thought they needed treatment and made an effort, and an additional 2.9\% felt they needed treatment but did not make an effort.

Duggan also emphasized that patient willingness to accept help often has a very narrow window-speed to treatment and the difficulty in navigating the health care system are important outcome determinants. Also important is acknowledgement by health care providers of our role in creating the epidemic and open discussion on how the stigma of addiction delays recognition and treatment for patients and their families. ${ }^{15}$
Speaker Botticelli indicated that the White House is on record as supporting the following OUD treatment paradigms: ${ }^{7}$

- Supporting MAT. The premise is that medication withdrawal and psychosocial treatment alone without medication show high rates of relapse.

- Working to expand access to evidence-based treatment by creating an inventory of treatment availability and working within Affordable Care Act and state-run health marketplaces to ensure proper resourcing.

The Vermont Blueprint for Health was presented by Speaker Tanzman as an example of best practices for the identification and treatment of OUD. ${ }^{12}$ A key part of the Vermont solution is access to substance abuse treatment, including the use of MAT (pharmacotherapy: buprenorphine and methadone) along with the following:

- Counseling and behavioral therapies

- Relapse prevention

- Recovery supports

- Services for chronic conditions

- Care management

- Health education

- Family support

In the Vermont Hub and Spoke model for opioid addiction, ${ }^{26}$ the "spokes" are usual care with team-based care for officebased practices (physicians and community health teams comprising nurse care managers, health coaches, social workers, and behavioral health clinicians). The "hubs" care for people with complex OUD disorders and mental health comorbidities (e.g., methadone treatment centers; Figure 2).

Speaker Daw discussed UPMC's MAT initiatives, which included the following: ${ }^{14}$

- Letters to providers notifying them of expanded patient access to MAT and encouraging training in MAT. Requires MAT prescribers to work with licensed drug and alcohol treatment providers to establish a treatment plan for the patient.

- Following MAT guidelines by allowing for no narcotic fills within 90 days of a buprenorphine fill and tapering patients off benzodiazepines.

- UPMC Health Plan best practices: Pain management DUR. Targets members in need of pain control by providing pharmacist and care management support.

\section{Forum Recommendations for AMCP}

The speakers and panelists recommended that a robust educational awareness campaign is needed that states the capabilities and benefits of holistic approaches to pain management and OUD prevention and treatment. This campaign should include a transparent, all-encompassing educational effort that shows which best practices are supported by a high strength of evidence. 


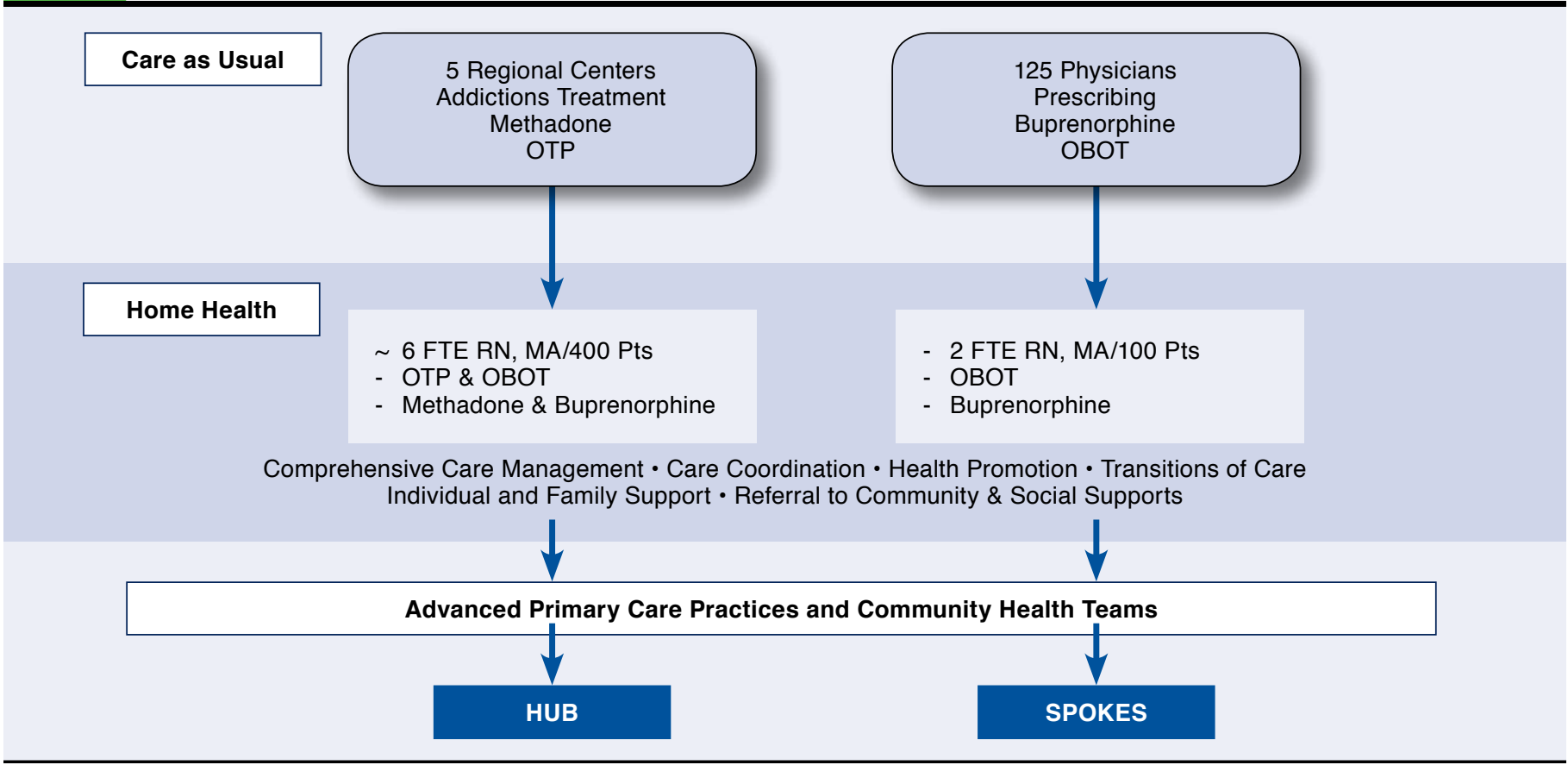

Source: State of Vermont. Vermont Health Homes for Opioid Addiction. Hub E Spoke. Program overview. April $2014 .{ }^{26}$

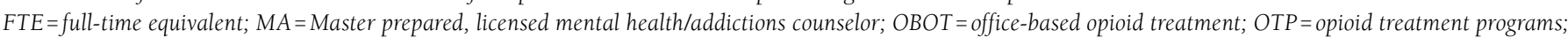
Pts = patients; $R N=$ registered nurse.

\section{Components of the Educational Plan}

Components of the proposed educational plan were presented as follows:

1. Promote evidence-based clinical guidelines and pain management and OUD treatment best practices. Pain management and OUD treatment should be driven by evidence-based clinical guidelines and best practices. The goal is to improve treatment outcomes and reduce the potential for OUD. P\&T committees should be encouraged to use evidence-based medicine when making or revising formularies and utilization management decisions. Managed care should share observational studies and best practices with each other through AMCP forums and meetings and other appropriate venues. MCOs should research best practices and publish findings in the Journal of Managed Care E Specialty Pharmacy or in other peer-reviewed journals. Best practices need to be disseminated and applied through local grassroots approaches to OUD prevention and treatment that include all stakeholders and community resources. Immediate practical efforts by AMCP might include the following:

a. Developing and conducting AMCP continuing education programs on pain management and OUD prevention and treatment. Educational content should address destigmatizing OUD by perhaps juxtaposing this with the role pharmacy played in this public health crisis. b. Developing an OUD prevention and treatment toolkit for members based on best practices.

c. Actively promoting quality standards for the treatment of OUD.

2. Promote a comprehensive, coordinated care approach. Pain management and OUD treatment require a more holistic approach among medical, pharmacy, behavioral, and mental health disciplines, with care coordination and collaboration among patients, family support, and providers (i.e., primary care physicians, specialists, pharmacists, and case managers). This coordination should occur across resources internal and external to the MCOs and should be seamlessly supported through a connected technology infrastructure, including interoperable PDMPs (e.g., integrating PDMPs into electronic medical records and health information exchanges), predictive modeling, and care pathways. The information technology structure needs to support a patient responsibility component. Patient engagement and improved access and speed to treatment are essential, and better care transitions are needed for patients at risk for OUD, especially between the emergency department (ED) and other sites. Patients being discharged from the ED should be educated about pain treatment alternatives, risks associated with treatment alternatives, proper 
disposal of unused medication, and, if OUD is suspected, treatment resources and support groups. Outcomes-based provider reporting and reimbursement models with shared or bundled reimbursement should be explored.

An immediate practical effort by AMCP might include forming a coalition with other key stakeholder organizations (e.g., America's Health Insurance Plans, Substance Abuse and Mental Health Services Administration, American Society of Addiction Medicine, and other medical societies, pharmacy benefit managers, MTM providers, OUD education associations, state boards of pharmacy and medicine, patient recovery groups, and researchers) to discuss the creation of a list of guiding principles for breaking the link between pain management and OUD.

\section{Conclusions}

Addressing the persistent prescription drug abuse problem and its resultant high societal and economic costs requires the coordinated efforts and actions of all stakeholders. Efforts to improve pain management outcomes and reduce the potential for OUD should rely on demonstrated evidence and best practices. Grassroots efforts involving local providers, organizations, community resources, and patient advocates are needed. AMCP should promote a more holistic evidence-based approach to pain management and treatment of OUD. This approach should actively engage the patient in the decision process and include care coordination with medical, pharmacy, behavioral, and mental health aspects of organizations, seamlessly supported by a technology infrastructure.

\section{Forum Attendees}

MICHAEL P. BOTTICELLI, Acting Director, Office of National Drug Control Policy (speaker); IRWIN “PETE” BROCK III, MD, Senior Vice President, Affordability, OptumHealth Behavioral Solutions; PHYLLIS BROOKS, RPh, Program Lead for Drug Utilization Review, Humana; DAVID BYRAM, Vice President, Market Access, Orexo; KELLY J. CLARK, MS, MBA, Medical Director, Medical Affairs, CVS Health; FREDERICK A. CURRO, DMD, PhD, Director, PEARL Clinical Translational Network, and Clinical Professor, New York University; JESSICA DAW, PharmD, MBA, Director of Clinical Pharmacy, University of Pittsburgh Medical Center (speaker); MIKE DUGGAN, Founder of Wicked Sober (speaker); JENNIFER ERENSEN, MPH, Associate Director, Health Policy, Purdue Pharma; JENNIFER FAN, PharmD, JD, Public Health Advisor, SAMHSA Center for Substance Abuse Prevention; WILLIAM FRANCIS, RPh, MBA, Vice President, Pharmacy Management Services, Medlmpact;
ARNOLD GAMMITONI, PharmD, Vice President, Medical and Scientific Affairs, Zogenix; MARY P. GHODS, RPh, Center for Drug Evaluation \& Research, U.S. Food and Drug Administration; PEGGY GREENBERG, RN, President, Peggy Greenberg Consulting and Training; SAIRA A. JAN, PharmD, MS, Clinical Professor, Rutgers, The State University, and Director of Clinical Pharmacy, Horizon BCBS of New Jersey; PAUL L. JEFFREY, PharmD, Director of Pharmacy, MassHealth; THOMAS KOWALSKI, $R P h$, Director of Clinical Pharmacy, Blue Cross Blue Shield of Massachusetts (speaker); JINHEE LEE, PharmD, Public Policy Advisor, SAMHSA Center for Substance Abuse Treatment; DIANE L. McNALLY, BSPharm, MS, Health Benefit Specialist, Centers for Medicare \& Medicaid Services; LYNNE E. NOWAK, MD, MBA, Medical Director, Express Scripts; JOHN F. PEPPIN, DO, FACP, Medical Director, Global Medical Affairs, Mallinckrodt; ALLIE SCHROEDER, PharmD, Clinical Research Fellow, University of Colorado Skaggs School of Pharmacy-Kaiser Permanente of Colorado; PETE SCHMIDT, MD, Medical Director, Depomed; JEFF STODDARD, MD, Vice President, Medical Professional Services, Alkermes; BETH TANZMAN, MSW, Assistant Director, Vermont Blueprint for Health (speaker); HEATHER THOMSON, MBA, MS, Director of Managed Care, kaléo; and LAURIE WESOLOWICZ, PharmD, Director II, Pharmacy Services Clinical, BCBS of Michigan.

AMCP STAFF: CHARLIE DRAGOVICH, Director of Business Development; BERNADETTE EICHELBERGER, Director of Pharmacy Affairs; JOHN MACKOWIAK, Editor-in-chief, Journal of Managed Care E Specialty Pharmacy; SUSAN OH, Assistant Director of Pharmacy Affairs; TODD SEGA, Senior Manager of Pharmacy Affairs; PUNEET SINGH, Manager of Education; and RUBY SINGH, Director of Education.

CORRESPONDENCE: Susan Oh, Assistant Director, Pharmacy Affairs, Academy of Managed Care Pharmacy, 100 N. Pitt St., Ste.400, Alexandria, VA 22314. E-mail: soh@amcp.org.

\section{DISCLOSURES}

The AMCP Partnership Forum on Breaking the Link Between Pain Management and Opioid Use Disorder and the development of this proceedings document were supported by Alkermes, Depomed, kaléo, Mallinckrodt, Orexo, Purdue Pharma, Teva, and Zogenix.

\section{REFERENCES}

1. Substance Abuse and Mental Health Services Administration, Center for Behavioral Health Statistics and Quality. Substance use and mental health estimates from the 2013 National Survey on Drug Use and Health: overview of findings. The NSDUH Report. September 4, 2014. Available at: http:// www.samhsa.gov/data/2k14/NSDUH200/sr200-findings-overview-2014.pdf. Accessed October 29, 2015

2. Birnbaum HG, White AG, Schiller M, Waldman T, et al. Societal costs of prescription opioid abuse, dependence, and misuse in the United States. Pain Med. 2011;12(4):657-67. 
3. Alliance of Community Health Plans. Ensuring safe and appropriate prescription painkiller use: the important role of community health plans. November 2012. Available at: http://www.achp.org/wp-content/uploads/ ACHP-Brief-Ensuring-Safe-and-Appropriate-Prescription-Painkiller-Usel. pdf. Accessed October 29, 2015.

4. Centers for Disease Control and Prevention. Unintentional drug poisoning in the United States. July 2010. Available at: http://www.cdc.gov/homeandrecreationalsafety/pdf/poison-issue-brief.pdf. Accessed October 29, 2015.

5. White AG, Birnbaum, HG, Mareva MN, et al. Direct costs of opioid abuse in an insured population in the United States. J Manag Care Pharm. 2005:11(6):469-79. Available at: http://www.amcp.org/data/jmcp/3.pdf.

6. Bohnert AS, Valenstein M, Bair MJ, et al. Association between opioid prescribing patterns and opioid overdose-related deaths. JAMA.

2011;305(13):1315-21. Available at: http://jama.jamanetwork.com/article. aspx?articleid=896182. Accessed October 29, 2015.

7. Botticelli M. ONCDP 101: The National Drug Control Strategy and Other Drug Policies. Presented at: The AMCP Partnership Forum: Breaking the Link Between Pain Management and Opioid Use Disorder; September 9, 2014; Alexandria, VA.

8. National Center for Health Statistics/Centers for Disease Control and Prevention. Unpublished special tabulations of 2011 multiple cause of death data. June 10, 2014.

9. Muhuri PK, Gfroerer J, Davies C. Associations of nonmedical pain reliever use and initiation of heroin use in the United States. Substance Abuse and Mental Health Services Administration, Center for Behavioral Health Statistics and Quality. CBHSQ Data Review. August 2013. Available at: http://archive.samhsa.gov/data/2k13/DataReview/DR006/nonmedical-painreliever-use-2013.pdf. Accessed October 29, 2015.

10. Cicero TJ, Ellis MS, Surratt HL, Kurtz SP. The changing face of heroin use in the United States: a retrospective analysis of the past 50 years. JAMA Psychiatry. 2014;71(7):821-26.

11. Office of the President of the United States. National Drug Control Strategy 2014. Available at: http://www.whitehouse.gov/sites/default/files/ ndcs_2014.pdf. Accessed October 29, 2015.

12. Tanzman B. Best practices for identification and treatment of opioid dependence. Presented at: The AMCP Partnership Forum: Breaking the Link Between Pain Management and Substance Abuse; September 9, 2014; Alexandria, VA.

13. Agency for Healthcare Research and Quality. The effectiveness and risks of long-term opioid treatment of chronic pain. September 2014. Available at: http://www.ahrq.gov/research/findings/evidence-based-reports/opoidstp. html. Accessed October 29, 2015.

14. Paulozzi LJ, Zhang K, Jones CM, Mack KA. Risk of adverse health outcomes with increasing duration and regularity of opioid therapy. J Am Board Fam Med. 2014;27(3):329-38. Available at: http://www.jabfm.org/content/27/3/329.long. Accessed October 29, 2015.

15. Duggan M. Patient perspective: system deficiencies that led to substance abuse. Presented at: The AMCP Partnership Forum: Breaking the Link Between Pain Management and Opioid Use Disorder; September 9, 2014; Alexandria, VA.
16. Office of National Drug Control Policy, Office of Public Affairs. Fact sheet: opioid abuse in the United States. February 11, 2014. Available at: http://www.whitehouse.gov/sites/default/files/ondcp/Fact_Sheets/opioids_ fact_sheet.pdf. Accessed October 29, 2015.

17. Daw J. Managed care lessons learned: pain management and substance abuse. Presented at: The AMCP Partnership Forum: Breaking the Link Between Pain Management and Opioid Use Disorder; September 9, 2014; Alexandria, VA.

18. Kowalski T. Opioid management program implementation 2012-2013. Presented at: The AMCP Partnership Forum: Breaking the Link Between Pain Management and Opioid Use Disorder; September 9, 2014; Alexandria, VA.

19. Centers for Medicare $\&$ Medicaid Services. Advance notice of methodological changes for calendar year (cy) 2016 for Medicare Advantage (MA) capitation rates, Part C and Part D payment policies and 2016 call letter. February 20, 2015. Available at: http://www.cms.gov/Medicare/HealthPlans/MedicareAdvtgSpecRateStats/Downloads/Advance2016.pdf. Accessed October 29, 2015.

20. U.S. Department of Health and Human Services, Office of Inspector General. FDA lacks comprehensive data to determine whether risk evaluation and mitigation strategies improve drug safety. Report OEI-04-11-00510. February 2013. Available at: https://oig.hhs.gov/oei/reports/OEI-04-1100510.asp. Accessed October 29, 2015.

21. Kelly C. FDA sentinel transition will involve expanding Rx safety data sources. "The Pink Sheet." February 23, 2015. Available at: https://www. pharmamedtechbi.com/publications/the-pink-sheet/77/8/fda-sentineltransition-will-involve-expanding-rx-safety-data-sources. Accessed October 29, 2015.

22. Tennessee Department of Health, Controlled Substance Monitoring Database Committee. Controlled Substance Monitoring Database. 2014 Report to the 108th Tennessee General Assembly, February 1, 2014. Page 5. Available at: http://health.tn.gov/statistics/Legislative_Reports_PDF/CSMD_ AnnualReport_2014.pdf. Accessed October 29, 2015.

23. Roberts AW, Skinner AC. Assessing the present state and potential of Medicaid controlled substance lock-in programs. J Manag Care E Spec Pharm. 2014;20(5):439-46. Available at: http://www.amcp.org/JMCP/2014/ May/18034/1033.html.

24. U.S. Government Accountability Office. Medicare Part D: instances of questionable access to prescription drugs. GAO-11-699. September 6, 2011. Available at: http://www.gao.gov/products/GAO-11-699. Accessed October 29, 2015.

25. Substance Abuse and Mental Health Services Administration. Results from the 2013 National Survey on Drug Use and Health: summary of national findings. NSDUH Series H-48. HHS Publication No. (SMA) 14-4853. Rockville, MD: Substance Abuse and Mental Health Services Administration; 2014. Available at: http://www.samhsa.gov/data/sites/ default/files/NSDUHresultsPDFWHTML2013/Web/NSDUHresults2013.pdf. Accessed October 29, 2015.

26. State of Vermont. Vermont Health Homes for Opioid Addiction. Hub \& Spoke. Program overview. April 2014. Available at: http://www2.leg. state.vt.us/CommitteeDocs/2014/Senate\%20Health\%20and\%20Welfare/ Substance\%20Abuse\%20Treatment/W Beth\%20Tanzman Vermont\%20 Health\%20Homes\%20for\%20Opioid\%20Addiction\%C2\%A6\%20Hub\%20 and\%20Spoke 4-23-2014.pdf. Accessed October 29, 2015. 